\title{
THE CONTINUING DEBATE OVER RESPONSIBILITY: AN INTRODUCTION TO ISOLATING THE CONDEMNATION SANCTION
}

\author{
HAROLD D. LASSWELL $\dagger$ \\ RICHARD C. DONNELLY†
}

In recent years, perennial questions about criminal responsibility ${ }^{1}$ have gone through another phase of active and sometimes vociferous debate. After World War II, both civilian and military leaders of defeated countries were prosecuted as war criminals under doctrines and conventions of international law that gave rise to controversies not yet ended. ${ }^{2}$ As a defeated or liberated nation put its house in order, many delicate problems involving the activities of wartime collaborators were resolved in various ways. ${ }^{3}$ The boom in world institution building, which shaped the United Nations and an auxiliary net of international organizations, made it necessary to consider issues of legal responsibility. ${ }^{4}$ Social revolution and national reconstruction have brought about

$\dagger$ Professor of Law and Political Science, Yale Law School.

$\dagger \dagger$ Professor of Law, Yale Law School.

1. Inasmuch as this entire article attempts to develop a theory of responsibility, it would be premature to define that term here. "Responsibility" has been used in several ways. For example, the British Royal Commission on Capital Punishment made the following observations :

The word "responsible," as Stephen pointed out, is used in one sense by lawyers, and often in quite another by medical men, and, we may add, by laymen, when discussing the relation of insanity to crime. For the lawyer "responsible" means only "liable by the law of England (or Scotland) to be convicted and punished for a criminal act." Medical men, on the other hand, sometimes use it as though it referred to some condition of mind, but more often as though it meant "liable to be punished under the law as it ought to be" if the law took account of modern medical knowledge. To the layman it means deserving of punishment according to the standards which ordinary men apply in daily life in deciding whether other people should be regarded as accountable for their actions.

Royal Commission on Capttal Punishment, Report 74 (1953).

See also Hart, Legal Responsibility and Excuses, in Determinism ANd FREedom in the Age of Modern Science 81 (Hook ed. 1958).

2. The extent of the literature is indicated by NeumanN, A Bibliography of the European War Crimes Trials (1951). See also Appleman, Military Tribunals and International Crimes (1954); Glueck, War Criminals: Their Prosecution \& Punishment (1944); Keenan \& Brown, Crimes Against International Law (1950); Stone, Aggression and Wordd Order (1958).

3. See Comment, Wartime Collaborators: A Comparative Study of the Effect of Their Trials on the Treason Law of Great Britain, Switzerland and France, 56 YALE L.J. 1210 (1947).

4. See, e.g., Comment, Genocide: A Commentary on the Convention, 58 YALE L.J. 1142 (1949); Johnson, The Draft Code of Offences Against the Peace and Security of Mankind, 
the revamping of criminal codes. ${ }^{5}$ Similar ferment in this country has manifested itself in comprehensive revisions of criminal legislation in Louisiana and Wisconsin, by movements for reform in other states, and, most significantly, by the Model Penal Code project of the American Law Institute. ${ }^{6}$ Where reconsideration has been less comprehensive, as in Great Britain, old controversies-for example, the merits of capital punishment ${ }^{7}$ - have nevertheless surfaced. Many countries have been perplexed by the problem of selecting and enforcing appropriate standards of sexual conduct and juvenile behavior. ${ }^{8}$ The extraordinary growth of psychiatry has challenged and confused earlier conceptions of the proper limits of both criminal and civil responsibility. ${ }^{9}$

Although these important developments are known to every informed observer, it is worth emphasizing that the terms and conditions in which responsibility is discussed are rooted in slow historic change. Since the sixteenth century, at least, the scientific view of the world has been more widely and fully perceived generation by generation. But how can "scientific determinism," much less the new "indeterminism,"10 be harmonized with "responsi-

4 INT'L \& Comp. L.Q. 445 (1955) ; Wright, Proposal for an International Criminal Court, 46 Am. J. INr'L L. 60 (1952) ; Revised Draft Statute for an International Criminal Court, Report of the 1953 Committee on International Criminal Jurisdiction (U.N. Doc. No. A AC. 65 L. 13).

5. Donnelly, The New Yugoslav Criminal Code, 61 YALE L.J. 510 (1952); Ancel, The Collection of European Penal Codes and the Study of Comparative Law, 106 U. PA. L. Rev. 329 (1958) ; Sellin, The Protective Code, A Swedish Proposal (1957).

For recent developments in the Soviet Union, see Karev, The Forthcoming Reform in U.S.S.R. Criminal Lare, with comment by Berman, Harv. L. Record, May 1, 1958, p. 1, col. 2; Berman, Soviet Law Reform-Dateline Moscow 1957, 66 YALE L.J. 1191 (1957); Lipson, The New Face of "Socialist Legality", Problems of Communism, July-Aug. 1958, p. 22. For an up-to-date discussion of recent developments in Russia and East Germany, see Kirchheimer, The Administration of Justice and the Concept of Legality in East Germany, 68 YALE L.J. 705 (1959).

6. Wechsler, The American Law Institute: Some Observations on Its Model Penal Code, 42 A.B.A.J. 321 (1956); Wechsler, The Challenge of a Model Penal Code, 65 HArv. L. REv. 1097 (1952).

7. Royal Commission on Capital Punishment, Report (1953); Koestler, Reflections on Hanging (1957); Prevezer, The English Homicide Act: A New Attempt To Revise the Law of Murder, 57 Colum. L. Rev. 624 (1957) ; Williams, The Homicide Act, 1957, 20 Modern L. Rev. 381 (1957); Allen, Book Review, 10 Stan. L. Rev. 595 (1958).

8. See, e.g., Committee on Homosexual Offences and Prostitution, Report, CMD. No. 247 (1957); Moder. Penal Code $§ 207$ (Tent. Draft No. 4, 1955); U.N. Secretariat, International Review of Criminal Policy, The Prevention of Juvenile Delinguincy, Nos. 7-8 (U.N. Pub. Sales No. 1955. IV. 10).

9. See Dession, Psychiatry and Public Policy, 5 Burfalo L. Rev. 48 (1955); Weinofen, The Urge to Punish (1956); Insanity and the Criminal Law-A Critique of Durham v. United States, 22 U. CHr. L. Rev. 317 (1955). See also Lasswell, Legislative Policy, Conformity and Psychiatry, in Psychiatry and the Law 13 (Hoch \& Zubin ed. 1955).

10. See Bridgman, Determinism in Mo'dern Science, and Munitz, The Relativity of Determinism, in Determinism and Freedom in the Age of Modern Science 43, 63 
bility" ?11 Year by year, the disjunction between the thought-ways of science and of pre-science has become more troublesome.

The recent debate over issues relating to responsibility is having productive consequences ${ }^{12}$ largely because contemporary discussion usually adopts an analytical framework in which legal activity is viewed as a decision-making process. Decisions are no monopoly of the courts, however. The term "decision" aptly describes not only the determinations of administrative agencies, executive organs, and legislatures, but also every act of participation in the shaping and sharing of power, including many phases of the national and international decision-making process. ${ }^{13}$

But how does studying the process of decision-making simplify or resolve the complexities that have barnacled the conception of responsibility? As one observes how responsibility doctrines are invoked in contexts of controversy and decision, the more general role of such conceptions is clarified. To analyze the operation of responsibility in context, one must ask the key questions: Who talks the language of responsibility? To whom? With what intended effects? With what realized effects?

Inasmuch as legal scholars customarily give special attention to the judicial arena, it is important initially to think about the significance of theories of responsibility in courts of law. One of the most obvious facts about a criminal trial is that the whole enterprise is characterized by expectations that responsibility must be discussed - expectations shared by the prosecutor, the defendant and his counsel, the jurors, the judge, and the public. ${ }^{14}$ Typically, the prosecutor asserts the responsibility of the defendant while the defendant and his counsel deny it. The jurors anticipate a judicial instruction regarding the matter; the public may or may not be in equipoise.

An impartial scientific observer interested in what actually takes place in an adversary proceeding can immediately arrive at a rather simple hypothesis. He sees the prosecutor seeking to influence the response of jury and judge in

(Hook ed. 1958). In connection with quantum theory and the resulting need for a more sophisticated mode of explanation, see Bonr, Atomic Physics and Human Knowledge (1958); Hetsenberg, Physics and Philosophy: The Revolution in Modern Science (1958).

11. Katz, Law, Psychiatry and Free Will, 22 U. CHI. L. Rev. 397 (1955) ; Hart, Legal Responsibility and Excuses, in Determinism ANd FreEdom In tHe Age of Modern SCIENCE 81 (Hook ed. 1958).

12. See Dession, The Technique of Public Order: Evolving Concepts of Criminal Law, 5 Buffalo L. Rev. 22, 41 (1955); Weinofen, The Urge to Punish (1956).

13. Codemakers-whether calling themselves legislators, commissioners, or reporters - cannot avoid committing themselves to canons of responsibility. See, e.g., Model PENAL CoDE $\S 4$ (Tent. Draft No. 4, 1955). And regulative bodies also must operate within a set of assumptions about responsibility. See Donnelly, The Law of Evidence: Privacy and Disclosure, 14 LA. L. REv. 361, 372 (1954).

14. See Alexander \& Staub, The Criminal, The Judge and the Public (1956); Reiwald, Society and its Criminals (1950). 
the direction of imposing a negative sanction, whether it be the death penalty, imprisonment, or a fine. He observes that the prosecutor anticipates an official and formal pronouncement of the defendant's responsibility, for example, by a verdict of guilty, as a prerequisite to the final sanction pronounced by the judge. By way of contrast, the observer sees counsel for the defendant trying to elicit a "no sanction" or a "lesser sanction" response. Nonetheless, the defense counsel shares the prosecutor's presupposition that the defendant must be found responsible before any ultimate sentence may be imposed. An examination of the behavior of judge and jury confirms the parties' expectations, for it appears that the decision-makers also look upon a finding phrased in the language of responsibility as at least logically a preliminary to the imposition of a deprivational sanction. The observer's "simple hypothesis," then, can be summarized by saying that when defendant $X$ is declared to be responsible, a characteristic is imputed to $X$ that makes of him an eligible target for negative sanctioning measures. This hypothesis applies to certain "civil" proceedings as well as "criminal" cases, although the terminology may vary among the categories of controversy. 15

Yet, despite the critical role played by findings of responsibility, the doctrine provides little guidance to the decision-maker when he must choose which negative sanction to impose upon a target individual or group previously deemed "responsible." Does a finding labelled "criminally responsible" carry uniform implications concerning the severity of the sanction to be applied? The label is formalistic and has no consistent contextual meaning. It cannot be affirmed, for instance, that sanctions directed against "criminal" targets are uniformly more severe than those imposed upon "civil" defendants. ${ }^{16}$ Nor can it be successfully demonstrated that "criminal" offenders always meet more intense expressions of community outrage or disrespect than "civil" losers. Evidently, no more than an erratic relationship exists between the language of legal responsibility and the facts of the decision-making process.

In estimating the incongruity between declarations of responsibility and the context of decision, one must gauge the degree to which a court deliberately "rationalizes" its response. The critical work of American legal realists has exposed that what a court says about past events or the traits of a defendant may have little, if any, "truth value" from the standpoint of an independent and competent observer who investigates the objective facts. ${ }^{17}$ In part, this inconsistency is attributable to the court's dependence upon information dis-

15. Dession, The Technique of Public Order: Evolving Concepts of Criminal Law, 5 Buffalo L. Rev. 22, 26 (1955).

16. Ibid.

17. See generally Llewellyn, Some Realism About Realism-Responding to Dean Pound, 44 Harv. L. Rev. 1222 (1931) ; Frank, Law and the Modern Mind 127-28 (1930). See also the selections from Cardozo, Haines, Hutcheson, Llewellyn, Frank and F. S. Cohen in Cohen \& Cohen, Readings in Jurisprudence and Legal Philosophy ch. 6 (1951). 
covered in proceedings that are usually adversary. Chiefly, however, the result reflects the judges' self-imposed demand to present a self-consistent response. ${ }^{18}$

The disjunction between legal theory and the social context is directly exhibited in the "moral" significance presently attached to the category of responsiblity. Our system of law has tended to employ responsibility in a manner that entirely lacks any standard or intended relationship to ethical norms. This ethical neutrality is epitomized by the "absolute or strict liability" offenses ${ }^{19}$ in which the notion of responsibility, qua sanctionability, is cut adrift from overtones of moral obligation. Therefore, to infer that $X$ has deviated from current ethical standards and sentiments when a court declares $X$ responsible and inflicts a deprivation upon him is often unwarranted.

However-and this is the point of greatest importance in the present context-the dissociation of responsibility from an evaluation in terms of rectitude is in no sense complete. "Responsibility" is one of the most heavily charged terms in our ethical vocabulary. We make everyday appraisals of one another in statements that include the words "responsible" and "nonresponsible." As a result, when the word figures among the terms of art in our legal vocabulary, it is bound to reverberate beyond the simple denotations of professional syntax. Quite commonly, so far as the conscience of the defendant or the impressions obtained by a newspaper reader are concerned, the declaration by a court that an individual or a group is "responsible" is equivalent to saying that the defendant is in some sense blameworthy and culpable. Other related words, notably "guilt," carry much heavier loadings of this kind, but, if anything, their emotional charge reinforces that which independently is connected to "responsibility."

To acquiesce in the present confusion of meaning is unwise. Steps should be taken, if appropriate ones can be proposed, to isolate the several roles played by doctrines of responsibility in our jurisprudence. To that end, we shall develop our theory of responsibility, and in so doing, shall consider the elements of the decisional process, briefly classify potential targets of the condemnation sanction, characterize offenders functionally, and discuss the policy implications of our contextual view.

At the outset, it is convenient to distinguish between two categories of decisions that are made by jurors and judges. One category is technical and the second is effective. The fact-finder is responding technically, for instance, when it makes a finding that is formally necessary to justify the conviction. The effectiveness of a response, on the other hand, is the degree of actual

18. Modern dynamic psychiatry has made commonplace the observation that conflicts between conscious and unconscious knowledge within a personality system may blind the individual to what the outsider perceives to be flagrant contradictions among his expressed perspectives. Contradictions that are freer of such conflicts, however, can be self-recognized and overcome. Social psychologists are actively concerned with these relationships. See Festinger, A Theory of Cognitive Dissonance (1957); Hovland, Janis \& Kelley, Communication and Persuasion (1953) and subsequent studies.

19. See the discussion in Model Penal Code $\S 2.05$, comment (Tent. Draft No. 4, 1955). 
indulgence or deprivation that it gives or imposes. The experienced lawyer presumably regards a finding of responsibility as technical. But the technical aspect does not necessarily or typically exhaust the total impact of the findings. The jury may characterize the defendant as "guilty"; the judge may affirm and embellish the condemnation by denunciations of a moral cast. ${ }^{20}$ Laymen may interpret the judge's language as an affirmation that a rectitude norm has been violated and that the defendant is being subjected to additional condemnation.

A finding of responsibility, then, comprises both a technical and a "condemnation" response, regardless of the words used to communicate the decision. It is a formal expression of censure and disapproval. The condemnation response is, in fact, a sanction, and a negative sanction at that. Speaking technically, lawyers are not accustomed to regard it as a sanctioning measure, but rather as a preliminary to sanction. ${ }^{21}$ Nonetheless, a contextual approach in studying the legal process requires us to honor actuality by classifying a finding of responsibility as a sanctioning instrument. The problems that arise are : What doctrine of responsibility should be recommended? Assuming that a finding of responsibility is a condemnation sanction, how can this sanction best be applied?

Presumably, a doctrine of responsibility should yield rational directives for sanctioning measures. Hence, simultaneous consideration of responsibility and condemnation sanctions provides an opportunity to explain and utilize a theory of responsibility by examining its implications for a sample sanctioning instrument. Inasmuch as a finding that a given defendant is responsible operates both as a condemnation sanction independent of any subsequent sanction and a prerequisite to such subsequent sanction, we advocate a two-pronged, functional theory of responsibility. As a technical finding, a declaration that a defendant is responsible must be employed with an eye to an ultimate outcome of the lawsuit that will maximize the social values our legal system is designed to nourish. As a self-fulfilling community evaluation, responsibility-condemnation must similarly be coordinated with the appropriate aims of legal sanctions. These discrete yet ever-related workings of a finding of responsibility are the keys to our theory of responsibility and to isolating the condemnation sanction.

\section{WORKINg TOWARd a TheORY}

This preliminary consideration of the role of a doctrine of responsibility in the decision-making process has disclosed historical and contemporary uncer-

20. See, e.g., Judge Leibowitz's castigation of Harry Gross, quoted in the dissenting opinion in People ex rel. Kern v. Silberglitt, 4 N.Y.2d 59, 63-64, 149 N.E.2d 76, 78-79, 172 N.Y.S.2d 145, 148-49 (1958).

21. Of course, the sanction imposed by the court following a finding of responsibility may itself be condemnatory in character. Royal Commission on Capital Punishment, RePORT 17-18 (1953) ; Ewing, Punishment as Viewed by the Philosopher, 21 CAN. B. REv. 102 (1943) ; Cohen, Moral Aspects of the Criminal Law, 49 Yale L.J. 987, 1007-26 (1940). 
tainties, inconsistencies, and confusions. Yet judges apparently look to theories of responsibility for guidance in choosing sanctions for particular targets. By the same token, the parties assume that some conception of responsibility will shield them from, or expose them to, the lightning of an adverse outcome. These expectations are legitimate only in the sense that one test of the rationality of a doctrine of responsibility is the extent to which it aids in target and sanction choices.

If any responsibility doctrine is to be of assistance, it must facilitate the five intellectual tasks ${ }^{22}$ that are always performed, however poorly or brilliantly, in making a decision. Phrasing the tasks as questions, the fully oriented decision-maker asks :

1. What value goals (preferred events) are to be maximized?

2. What future events are likely to occur if as little action as possible is taken in this situation?

3. What future events are likely if alternative policies are adopted?

4. In considering the past as it relates to value goals, what trends are relevant?

5. What scientific findings are relevant?

\section{Clarification of Goals}

Observers of the legal process perceive that systems of legal order can be operated with emphasis either upon the "ideal" goals of the community or upon more "workable" norms that prevail in context. Since ideal aspirations are more often honored in the breach than in the observance, norms that enjoy a prospect of achieving high levels of effective acceptance may more optimistically be applied. As a result, decision-makers are well advised to look beyond the words of a given body of authoritative language in order to discover a realistic factual basis. And, if the relevant context is to be comprehended by a decision-maker, appropriate communicative methods must be used; consequently, it is essential for the court to be well informed about the pertinent body of historical and scientific information.

But the judge is no automatic mechanism of mediation between past practice and a present, concrete case. What degree of conformity should he try to maintain between a proclaimed or prescribed norm and the conduct of parties who come before him as defendants? In a given situation, should he attempt to increase the degree of future conformity or should he give up this regulatory attempt as a bad job disproportionately costly in social effort? If varying

22. Lasswell \& McDougal, The Jurisprudence of a Free Society: Studies in Law, Science and Policy (mimeographed materials, Yale Law School 1954); Lasswell \& McDougal, Legal Education and Public Policy: Professional Training in the Public Interest, 52 Yale L.J. 203 (1943) ; Lasswell, The Political Science of Science, 50 Am. Pol. ScI. REv. 961, 977-78 (1956); McDougal, The Comparative Study of Law for Policy Purposes: Value Clarification as an Instrument of Democratic World Order, 61 YaLE L.J. 915 (1952). 
standards are current in different subcommunities, with which shall the decisionmaker ally himself? For instance, if some areas are inhabited by recent immigrants from another culture, or if there are discernible behavioral differences among upper, middle, and lower classes, or if great yet divergent interest groups cut across lines of class, or if conduct has been affected by crises of war preparation, war itself, economic recession, or inflationary boom, which standards are to be taken as "law" ?23

Queries of this kind indicate that the rational judge cannot properly regard himself as a blind instrument of something vaguely called the "sense of injustice" or "the community norms" or "the laws" (in the dubious sense of the formal code). The enlightened decision-maker must choose his own overriding goals (preferred events). In this way, he is able to act deliberately as an ally of one set or another of past practices, which he then protects or extends while he operates within the limits of a social role that continues to depend upon obtaining support from the body politic.

Accordingly, the first step in developing a doctrine of responsibility is to be as explicit as possible about the values postulated in order to clarify the character of the preferred events which it is the responsibility of the judge, and indeed of the legal system in its entirety, to protect and extend. We postulate "human dignity" as the ideal norm and, in so doing, refer to a society in which the practices of daily life and the institutions of the social order are brought progressively into harmony with that norm.

Thus, our overriding goal values are substantially identical with the principles articulated in the Universal Declaration of Human Rights. ${ }^{24}$ These ideal norms are approximately equivalent to the highest aspirations of American, Western European, and, evidently, many other great traditions. We do not intend to justify these goals now ; rather, we assume them for present purposes and concern ourselves with questions that arise in seeking to harmonize the sanctioning activities of a democratic body politic with the ultimate valuehuman dignity.

Undoubtedly, reference to human dignity provides a phrase rich in tradition and one which comprehensively characterizes the long-range objective of any society that aspires toward freedom. The principles of the Universal Declaration are steps in the direction of specifying the practices-the routines of interaction in the social process-which we accept as compatible and consistent with the fundamental goal. But there is a gap-the distance that often separates even the relatively specific principles of the Declaration from the prevailing institutions of a given system of public order. A judge must share in the never-

23. Some of these problems are discussed in Mannheim, Some Aspects of Judicial Sentencing Policy, 67 YaLE L.J. 961 (1958).

24. YearboOK OF THE UNITED NATIONS 1948-1949, at 535-37 (1950); Bebr, International Protection of Human Rights and Freedoms, 29 PHIL. L.J. 312 (1954) ; McDougal \& Leighton, The Rights of Man in the World Community; Constitutional Illusions Versus Rational Action, 59 Y ALE L.J. 60 (1949); Lauterpacht, The Universal Declaration of Human Rights, 25 BRIT. YB. INT'L L. 354 (1948). 
ending reappraisal of the degree of conformity between the details of life and the principles which they are supposed to follow, exemplify, and strengthen.

If we were engaged upon an exhaustive application of our conception of responsibility to the United States (which we are not), it would be necessary to itemize the components of the national system of public order, and to submit a provisional characterization of how these components conform to our postulated value goals and principles. In any event, to indicate concretely what is meant by the system of public order which it is the function of the legal system to defend and perfect, we specifically refer to the fundamental features of the social process viewed as "men pursuing values through institutions using resources." 25 To pursue values is to shape and share outcomes like wealth and well-being. To operate in harmony with the general goal of human dignity is to favor relatively broad participation in valued outcomes. We classify institutional practices according to their focus upon each major value. The basic schemes of value distribution and the most important institutional patterns comprise the system of public order.

So far as our domestic political institutions are concerned, federalism, the tripartite separation of authority, the presidency, bicameralism, and adult suffrage are immediately prominent. As to economic institutions, America is strongly committed to the ideology of free private enterprise qualified by varying degrees of dependence upon government in multifarious contexts. In family affairs our culture approves monogamy, or, more accurately, sequential monogamy. We protect freedom of worship and expect the churches to generalize and legitimatize basic conceptions of rectitude. Free universal education and freedom of the press are among the doctrines more or less effectively realized in the sphere of skill and enlightenment. To an increasing extent, we expect the community as a whole to concern itself with the psychic integrity of its members. Although the dominant ideology in the realm of respect relations is anticaste, admittedly the practice in many localities is otherwise.

With these reminders of the system of public order which it is the role of our legal system to protect and fulfill, we can specify more precisely the function of courts and sanctions. As previously noted, the courts are chiefly engaged in the applying function, although they do not have a monopoly of this function, nor does the work of judicial tribunals exclude all other functions. Many organs of government besides courts use sanctions. The condemnation sanction, for instance, may be used by the President when, in his official role, he casti-

25. Lasswell \& McDougal, The Jurisprudence of a Free Society: Studies in Law, Science and Policy 1 (mimeographed materials, Yale Law School 1954). This is the framework within which the late Professor George Dession of the Yale Law School developed his reinterpretation of the criminal law field. In preliminary form his views are reflected by the arrangement of cases and materials in his Criminal Law, Administration and Public Order (1948), and, in a more developed state, by his article, The Technique of Public Order: Evolving Concepts of Criminal Law, 5 Buffalo L. Rev. 22 (1955). Both authors of the present article desire to make blanket acknowledgement of their late colleague's fundamental contribution to the stock of conceptions within which the present analysis took shape. 
gates those who "peddle influence" and seek to corrupt the Government. To be sure, these declarations are not sanctions in a technical sense of the word; but they nevertheless sometimes operate as effective, informal, coercive measures. They are verbal deprivations imposed in the name of the community by an official who is castigating target groups and individuals for having violated community norms. Presumably, the President expects to diminish the chance that these or other individuals will offend again. In the most inclusive sense, a community sanction is a practice which is expected to increase the probability of future conformity to community norms; thus, the meaning comprehends informal verbal pressures as well as legal deprivations. ${ }^{26}$

\section{Estimating the Future: Projections and Alternatives}

After specifying the kinds of goal values and instrumental institutions that compose our community ethos and order and form the object of legal sanctions, we face the next step in outlining our doctrine of responsibility. In addition to suggesting a set of overarching goals, we must attempt some guidance concerning the ways in which valid inferences about the future can be madean attempt involving the second and third intellectual tasks enumerated above.

The future is crucial; all decisions accomplish their results in the future and not in the past. The decision-maker has a number of alternatives open to him whose net impact upon preferred values and institutions it is his job to assess. One ever present alternative is to do the least possible. Considering the future on the assumption that this alternative is chosen is "projection." Typically, there are several more alternatives before a judge; for each, the question is what will be the effect of selecting target $A$ for the application of sanction 1 or 2 or 3 .

A rational guide to final decision must, therefore, classify the possible targets which the decision-maker should contemplate before coming to a final conclusion. All controversies before a court can be classified as "public" or "private." In a public controversy, a deprivation of public order is alleged; hence, the representatives of the community appear as parties, as in the traditional "criminal" action. In a private controversy, a deprivation of private values is alleged. And since the deprivation is not large enough, or strategically enough placed, to imperil the system of public order, representatives of the

26. In the present context, we are examining all the activities performed by courts in the administration of sanctions. Our discussion is more narrowly pointed toward what are conventionally called criminal cases. The proposed theory of responsibility defines the field of criminal law more narrowly than it has been defined in the past, yet our theory has ramifications beyond the criminal law so viewed. The first step has been to state the goal values (desired outcomes) that we assume to be appropriate for the judges exerting community authority in a body politic whose general commitment is to the dignity of man. In the United States, specifically, the preferred institutions that constitute our system of public order are not difficult to designate. The specific goal of sanction administration is to protect and fulfill the overriding aim of freedom by defending and modifying these institutions. 
community do not appear (in their official capacities) as parties. We shall begin with public controversies and draw up a check list of potential sanctionable targets ordered as "groups" or "roles." The former term emphasizes individuals; the latter impersonally characterizes a pattern of activity or position in the social process. We begin with groups.

\section{Direct Targets}

Judged Offenders. In this category come all litigating parties whom the court has currently judged to be offenders, or who have a record of having been so judged by other courts. In the ordinary work of adjudication, spokesmen of the community see themselves as most immediately confronted by the problem of how to proceed in dealing with those who have been officially designated as offenders.

\section{Indirect Targets}

Undetected Offenders. That a community's law-enforcement machinery is bound to fall short of infallible detection of individuals who have deviated from community norms, and who, if apprehended, would be judged to be offenders, is widely recognized. ${ }^{27}$ Yet, the sanctions currently applied to known offenders probably also affect the future conduct of those whose deviations have not been discovered. ${ }^{28}$

27. Crimes that are rarely reported are consensual sex acts, petty thefts, frauds, blackmail, traffic or motor vehicle violations, gambling, prostitution, black-market and other white-collar violations. Sellin, The Significance of Records of Crime, 67 L.Q. REv. 489, 494-99 (1951); Sutherland, Principles of Criminology 25 (5th ed. Cressey rev. 1955).

Sellin reports that the number of cases of shoplifting known to three Philadelphia department stores was greater than the total number of thefts of all kinds in the entire city which were known to the police. Sellin, Research Memorandum on Crime in the DePRESSION 69 (1937).

From November 1, 1947, to April 30, 1948, 1,576 persons were apprehended by store detectives for thievery from four stores in the Loop area of Chicago, but in only 137 cases was a report made to the police department either as to the offense or the person caught in the offense. Letter from Virgil W. Peterson, cited in TAFT, CrIminology 21 (1950).

In New York State, the only ground for divorce is adultery. Every time a divorce is granted, therefore, a judge certifies to his belief that adultery was committed by the defendant husband or wife. But the left hand of the law does not know what the right hand is doing. In the year 1948, for example, approximately 6,000 divorces were granted in New York City alone, yet the Annual Report of the Police Department for the same year does not disclose a single arrest for adultery. Ploscowe, Sex and the Law 156 (1951).

And a recent study of the "bad-check problem" in the State of Nebraska concluded that: "On the average, only about two per cent of the bad checks returned by the bankers get to the officials; and instead of prosecuting as required by law, the officials are chiefly engaged in collecting the checks under threat of criminal prosecution." BEUTEL, ExPERIMENTAL JURISPRUDENCE 406 (1957).

28. This is particularly true of youthful offenders. An important recent book states: Theft by juveniles, for example, is so common as to be almost universal. The delinquency laws are so broad that almost every child could conceivably be pro- 
Potential Offenders. For similar reasons, sanctions are often imposed with persons other than the immediate offender in mind. Society expects that individuals who as yet have performed no offense may be deterred from doing so in the future. The expectation relates not only to an offense of the same category as that sanctioned but also to those of different categories. ${ }^{29}$ A generalized "lawabiding" response is believed to be cultivated by at least some sanctioning measures.

Erroneously Judged Offenders. Another apparently inevitable characteristic of law enforcement is that innocent parties are sometimes convicted..$^{30}$ Occasionally, officials discover their errors and admit them..$^{31}$ But a number of undetected or unredressed cases may be extant at any given time. The future conduct of these unfortunates will be affected by the deprivations inflicted upon them and, furthermore, they will in all probability respond attentively and sensitively to news of current sanctioning activities.

Other Members of the Public. This category refers to members of the community considered as active citizens rather than as individuals who are potential violators of the law. Judges are not always unaffected by the criticisms that they expect to receive from professional colleagues, friends, the mass media, and other elements of the public at large..22 Presumably, too, judges are sometimes

cessed as a delinquent. But for most of these children nothing is done and the delinquency matures not into youthful or adult crime but rather into generally lawabiding behavior. This is true even of the youthful burglars and rapists, many of whom are never caught and almost all of whom mature into average law-abiding citizens.

Rubin, Crime and Junenile Delinquency 95 (1958).

29. Andenaes, General Prevention-Illusion or Reality?, 43 J. CRIM. L., C. \& P.S. 176 (1952).

30. Borchard, Convicting the Innocent (1932); Frank \& Frank, Not Guilty (1957); Koestler, Reflections on Hanging (1957); Donnelly, Unconvicting the Innocent, 6 VAND. L. Rev. 20 (1952).

31. In United States v. Kaplan, Judge Weinfeld was persuaded "that the prosecutor's view that an innocent man has been convicted is correct and that a grave miscarriage of justice has taken place.” 101.F. Supp. 7, 11 (S.D.N.Y. 1951). He reluctantly concluded, however, that no legal procedure existed for freeing Kaplan and that his only source of redress was executive clemency. For some inexplicable reason Kaplan's application for pardon was denied. Frank \& Frank, Not Guilty 111 (1957). See also Donnelly, Unconvicting the Innocent, 6 VAND. L. Rev. 20 (1952).

32. In 1939, Thomas. J. Pendergast, a party leader in Kansas City, Missouri, and Robert E. O'Malley, Superintendent of the Insurance Department of Missouri, pleaded guilty to attempting to evade the payment of income taxes on amounts received by them in connection with the settlement of litigation on fire insurance premium rebates. In a long memorandum, District Judge Otis listed the principles governing his sentences and dealt with certain criticisms as of the sentences as too lenient. He said in part:

This memorandum has been written and filed for the express purpose of submitting it for publication in the Federal Supplement to the end that there may be in the literature of the legal profession some record of two cases which attracted great national interest and which presented problems difficult of solution. What made the solution of the problems involved the more difficult was the fact that 
influenced by anticipated effects of a decision upon the stability of the community's political process..$^{33}$

In sum, any sanction, whether it be a penal sentence or a public reprimand, must be gauged as it affects not only the particular defendant in the immediate lawsuit but also all other target individuals and groups subject to its radiated

even as they were presented one could hear, figuratively speaking, the imprecations upon defendants of an outraged and injured populace.

Pendergast was sentenced on Monday, May 22, 1939. Five days later, Saturday, May 27th, O'Malley entered pleas of guilty and was sentenced. In the interim there was both widespread approval by eminent jurists, lawyers and editors of the Pendergast sentence and also the most violent criticism. The criticism certainly was sincere, but hasty, unanalytical, spoken and written apparently in complete blindness to the particular crimes for which sentences had been imposed and to the solemn obligations of the judicial oath. ... The theory of the men (not one of them ever had been charged with the responsibility of imposing a sentence in a criminal case) who cried out against the judge with much more vigor than ever they had cried out against the "Boss" was that Pendergast should have been punished because he had been "Boss," because he had been suspected of various offenses against the state and city, because as one put it, "of the backgound." The judge, it was said, had "let the community down," as if the offense for which punishment was imposed was an offense against "the community." Pendergast should have been required to pay not only for the crimes with which he was charged, but also for all his sins and all the sins of all his followers.

These principles seem to me now as they seemed on Monday to be true and sound. Perhaps I should have ignored them in the Pendergast case alone. Perhaps I should have ignored in that one case precedents and principles and the commands of reason. Perhaps I should have yielded to passion and hatred and revenge. I am glad I did not yield.

United States v. Pendergast, 28 F. Supp. 601, 602, 607, 609 (W.D. Mo. 1939). Perhaps the classic statement of the problems of a judge in imposing sentence is Ulman, THE Trial Judge's Dilemma: A Judge's View in Probation and Criminal Justice 109 (Glueck ed. 1933).

33. Consider, for example, the remarks of Judge Kaufman in the Rosenberg case:

The issue of punishment in this case is presented in a unique framework of history. It is so difficult to make people realize that this country is engaged in a life and death struggle with a completely different system. This struggle is not only manifested externally between these two forces but this case indicates quite clearly that it also involves the employment by the enemy of secret as well as overt outspoken forces among our own people. All of our democratic institutions are, therefore, directly involved in this great conflict. . . .

I consider your crime worse than murder. Plain deliberate contemplated murder is dwarfed in magitude by comparison with the crime you have committed. In commiting the act of murder, the criminal kills only his victim. The immediate family is brought to grief and when justice is meted out the chapter is closed. But in your case, I believe your conduct in putting into the hands of the Russians the A-bomb years before our best scientists predicted Russia would perfect the bomb has already caused, in my opinion, the Communist aggression in Korea, with the resultant casualties exceeding 50,000 and who knows but that millions more 
impact. Thus, a finding of responsibility cannot be thought to bear solely upon a single defendant in most instances. It must be viewed as both an end and a means (to roughly the same end) for all relevant targets. And, by classifying a defendant-the direct target of one sanction-the identity of shifting indirect targets is revealed. Conceivably one individual can play roles and subroles that fit into all the categories mentioned. An offender may be held responsible for an act that he did not commit, and thus fall within the first and fourth categories. But he may have committed other offenses, or the same offense on a different occasion, and thus also fit into the second category. He may be among the potential offenders of category three; and he may exercise some influence as a member of the commenting or voting public. His multiple role invokes a corresponding multiplicity of indirect targets as well.

\section{The Use of Trend and Scientific Knowledge}

The questions we raise about the future provide a guide for thinking about future events and for asking selective questions about the past (up to the "knife edge" present). Conversely, each category of "role" or "group" mentioned as important in the future must be identified, to a very considerable extent, on the basis of information about the past. Suffice it to say for the moment that in discussing the first two steps-goal clarification and future projections-we are contributing to the clarification of the two remaining intellectual tasks performed in every decision, namely, the consideration of trends and scientific conditions.

of innocent people may pay the price of your treason. Indeed by your betrayal you undoubtedly have altered the course of history to the disadvantage of our country. . . .

In the light of the circumstances, I feel that I must pass such sentence upon the principals in this diabolical conspiracy to destroy a God-fearing nation, which will demonstrate with finality that this nation's security must remain inviolate; that traffic in military secrets, whether promoted by slavish devotion to a foreign ideology or by a desire for monetary gains must cease.

Record, vol. 2, bk. 4, pp. 1613-15, Rosenberg v. United States, 344 U.S. 838 (1952).

See also United States v. Hurt, 9 U.S.C.M.A. 735, 27 C.M.R. 3 (1958), affirming the conviction and death sentence of an Army sergeant who was charged with raping and murdering a five-year-old Okinawan girl. Apparently, feeling was so high against Americans that the commanding general found it necessary to consult with "the civilian Chief Executive, the Speaker of the Legislature, the Chief Justice of the Ryukyu Islands, the President of the University of the Ryukyus, and the President and Managing Editors of the civilian newspapers." Id. at 759.

The judge may believe that mobs are likely to form in protest against. certain possible actions of the court in dealing with a defendant. Mob action may even be expected to turn into rebellion, secession, or social revolution. We place these contingencies here rather than in preceding categories, despite the fact that potential offenses are involved, because of the importance of considering public security in each case. The first four categories might be reclassified as one type of role-the offender-and the fifth category as another type of role-the citizen. Such a reclassification would serve to emphasize that one individual may perform more than one role relevant to the present analysis. 
The utility of reverting to information about the past is even more evident when we outline the problems that arise in connection with the selection of a negative sanction. Needless to say, the important consideration in imposing a negative sanction is whether results will follow that are consonant with the ends sought or whether the objectives of the legal order can be more consistently or compatibly attained through other means such as a preventive welfare program or an offer of a reward or incentive to behave. The decisionmaker must ask: "If a negative sanction (such as condemnation) is applied against a defendant, what probability is there that his conduct will be modified toward conformity?" Or, phrasing the same question another way: "Is the defendant educated or educable?" This is to ask the final, effective question: "Is he sanctionable, and how?"

In raising these questions, the decision-maker is inquiring into the present predispositions of the defendant as they are revealed by information about his past in order to arrive at an estimate of how he will respond to an environment that is deliberately made deprivational as a consequence of his conduct. Obviously, it is within the power of the decision-maker, acting on behalf of the community, to affect the conduct of the defendant by moulding the environment; deprivational environments are part of the standard pattern of community life in the sense that all participants in the community know that deprivations follow deviations from a norm. This is part of the "standard environmental exposure" characteristic of the culture.

Lay and scientific observation alike affirm that at any given phase of his career line an individual may have escaped exposure to standard social environments. Hence, he may not share those predispositions that enable most men to benefit from the cues that are provided in the social context. Or, an individual may have been exposed to standard environments, yet some factor largely beyond his control interfered with the advantage he otherwise would have gained from the experience. Other individuals have acquired the norms and techniques of the social situation, but are unable to live up to the acquired patterns due to intervening, specifiable events.

In the light of these distinctions, our conception of a proper doctrine of responsibility becomes more explicit. If, an individual is educated in the standard norms and techniques of the body politic, he is educable in the sense that can be expected to respond in a standard way to the standard practice of enduring a deprivational environment after breaching a norm. He can be called "responsible" and thereby made eligible for these exposures, these sanctions. If on the other hand, the defendant is not educated and if he is not educable (unless his deeper predispositions are transformed), he is not responsible; he is a correctional ${ }^{34}$ rather than a sanctioning problem. He does not learn in

34. The term "correctional" or "corrective" is used by us without "penal" or "criminal" connotations. We are aware that these connotations are often present, yet alternative categories typically suffer from similar disadvantages. The perspective with which we view the "corrective" problem is outlined in Dession \& Lasswell, Public Order Under Law: The Role of the Advisor-Draftsman in the Formation of Code or Constitution, 
standard environments and must either be permanently insulated by withdrawal from the social context or removed until he has been made educable, educated or both by reconstruction. The particular corrective measure to be applied depends upon this judgment.

This conception of responsibility is conducive to classifying offenders according to their probable responsiveness or nonresponsiveness to the various dispositional measures at the community's command. As our specimen measure, we shall refer to the condemnation sanction in explicating each category. The exercise will portray how our doctrine of responsibility provides a guide for predicting the impact of a condemnation sanction and for considering the context in which judges must make up their minds.

The categories of offenders are as follows:

The Immature. The immature are not expected to benefit from experience to the same extent as adult members of the community do. Children and young people must struggle continually to control impulses they have mastered insufficiently. Although the basic impulses of man continue through life, common observation reveals that young people are less likely than adults to have perfected a workable conscience-largely an automatic agency of internal control. ${ }^{\mathbf{3 5}}$ Indeed, maturity in our civilization consists of achieving a culturally standard level of internal responsibility for one's conduct. ${ }^{\mathbf{3 6}}$ The salient characteristic of a mature person is that he adapts his conduct to realistic estimates of its consequences. He learns rather quickly from successes and failures; particularly, he is able to learn by hearing about the experiences of others. The sanctioning provisions of a legal code are for the most part aimed at "standard learners," at "typically educable" members of the community. If enforcible deprivations are provided for deviational conduct, the mature members of the community are expected to take these possible deprivations into account as potential costs in assessing the balance of indulgence and deprivation attendant upon behavioral alternatives. Furthermore, if these calculated risks are taken and an individual "doesn't

65 YALE L.J. 174 (1955). There the major codes of a legal system are classified into five categories that are called supervisory, regulative, enterprisory, executory, and corrective. The supervisory code relates to the private activities in respect to which the community decision-maker operates in the role of umpire at the initiative of the parties. The regulative code includes the standards to be applied, at the initiative of the community, to the collective stream of private activities (for example, an action to abate a nuisance). The enterprisory code covers the operations under continuing administration by the government, notably organized military and police coercion, together with whatever operations come within the scope of civil and nonpolice administration. The executory code (or perhaps more felicitously, the constitutive code) deals with the organs and competences of those who participate in the community process of putting prescriptions into effect. We speak of "sanctioning measures" as part of each of the foregoing four codes. In order to give prominence to the relatively new conception of the "corrective," the term was used to designate the fifth subcode. The distinctive task of the corrective code is to specify the measures appropriate for the nonresponsible-the uneducated or uneducable.

35. ERIKson, Childhood and Society (1950).

36. Erikson, Growth and Crises of the "Healthy Personality," in PERsonality in Nature, Soctety, ANd Culture 185 (2d ed. Kluckhohn \& Murray 1955). 
get away with it," the sanction is (or can be) loaded to such a level that the target will learn to give more weight to the cost side of future deviations.

Significantly, immature individuals are especially likely to be influenced by condemnation sanctions. In our civilization, at least, the vocabulary parents and teachers address to children is full of terms affirming or implying standards and judgments of rectitude: "right," "wrong," "good," "bad," "righteous," "sinful." Children also employ the vocabulary of rectitude in coping with adults and seeking to establish a moral justification for their own demands. ${ }^{37}$ Still further, the vocabulary addressed by children to one another is full of this idiom, as is amply confirmed by studies of the language of children at play. ${ }^{38}$ Another manifestation of the process is the language used by the child when he is talking (and thinking) to himself. ${ }^{39}$ At certain periods of growth, the typical preoccupation of young people with moral questions is great and is reflected in diaries, in attendance at religious exercises, and generally by the use of moralizing maxims. ${ }^{40}$

The Uninformed (Unassimilated). Some individuals simply are unable to take advantage of the warnings of a legal code because they are psychically or physically removed from the cultural setting which is taken as a premise by the code makers. By the uninformed, we mean those who, though they may be mature and may have enough native talent to learn the patterns of culture, have had insufficient access to an environment that would instill them with a command of the basic norms and techniques of a given social setting. One obvious instance of the unassimilated is the newly arrived and wholly untutored immigrant from a sharply contrasting culture. But the class of the uninformed transcends that of the immigrant. Within the confines of any large-scale society exist subcommunities whose members lack access to the schooling and other opportunities needed to assimilate the dominant norms and techniques of the culture: isolated religious communities and remote and parochially-centered villages in the hill country or in other habitats shut off from communication

37. See the writings of Jean Piaget, particularly his The Language and Thought of the Child (Warden transl. 1926); Judgment and Reasoning in the Child (Warden transl. 1928); The Child's Conception of the World (Tomlinson transl. 1929); and The Moral Jungment of the Child (Gabain transl. 1932).

38. An exhaustive guide to the Language Development in Children, including "good" and "bad" categories of reference, is by Dorothea McCarthy, in Carmichael, MANUAL of Child Psychology 476 (1st ed. 1946).

39. The conscience of the individual depends upon incorporating as demands "of the Self by the Self" the demands that are made upon the primary ego of the child by the surrounding social environment. The soliloquies of the child that are often overheard by adults are part of this process. A particularly careful account of the growth of the self as put forward by George Herbert Mead is Natanson, The Social Dynamics of George H. Mead (1956). Sigmund Freud's hypotheses about the acquisition of conscience are abundantly considered in The Psychoanalytic Study of the Child (annual since 1945).

40. The adolescent phase of development in our civilization is well known for the "moral" problems that young people face. In this connection, see Symonds, Adolescent Fantasy; An Investigation of the Picture-Story Method of Personality Study (1949). 
with the main centers. ${ }^{41}$ A condemnation sanction addressed to an uninformed target often is entirely incomprehensible to him and, in many if not all such circumstances, evokes a sense of injustice against the seeming arbitrariness of the measure. ${ }^{42}$

The Defective and Diseased. No one will deny that educability can be impaired by congenital or other organic defects, or by primarily functional diseases. ${ }^{43}$ The mere existence of a defect or disease does not, of course, automatically consign the individual to the category of nonresponsibility. A determinative connection must be established between the pathological condition and ineducability.

Any theory of responsibility is severely tested by the deviational conduct of an individual who suffers from no discoverable organic pathology, but who is prevented from making a normal assessment of cost by seemingly unmanageable internal factors. In extreme cases, the individual may spend much of his waking life struggling against a desire to perform an act he abhors and recognizes as having costly consequences, only to be seized by an intense desire to complete such an act, a desire that overwhelms conscious barriers. Despite conscious perception of cost (save perhaps during a moment of "seizure"), the individual is unable to apply his self-appraisal effectively. ${ }^{44}$ In the language of the redoubtable and preoccupied New England lady who walked into a tree, she "saw it," but she "did not realize it." Furthermore, the same internal factors may exert such complete control over his conduct that the individual is unaware of any deficiency in his judgment despite repeated clashes with the machinery of public order. From the point of view of personality development, these individuals remain chronically immature as the result of early regression and may regress to acutely rebellious, destructively aggressive, wildly suicidal, or related extremes of conduct. ${ }^{45}$ The common element in functional disorders of educability should not be phrased in terms of irresistible impulse, in the legal sense, but as "compulsiveness" or "compulsivity," so as to emphasize the graduated nature of these motivational systems. Such "line drawing" calls for an examination of the whole personality context.

41. See Keedy, A Remarkable Murder Trial: Rex v. Sinnisiak, 100 U. PA. L. Rev. 48 (1951).

42. See Young, American Minority Peoples 246 (1932): "If our desirable penal objectives may be said to be the protection of society and its members from criminal injury, and not just revenge, why not extend the principle of individualization to minorities, as is already being done in a haphazard, occasional manner and has been done more thoroughly for our Indians and Negroes in slave days?"

43. Functional diseases are those free of organic lesions sufficient to account for the pathology. In this connection, we recognize, there are very troublesome questions of drawing a definitional line.

44. See the interesting case of United States v. Kunak, 5 U.S.C.M.A. 346, 17 C.M.R. 346 (1954), and Dr. Guttmacher's discussion of it in Model Penal Code § 4.01, app. B, at 175 (Tent. Draft No. 4, 1955).

45. See Cleckley, The Mask of Sanity (3d ed. 1955); Guttmacher, Diagnosis and Etiology of Psychopathic Personalities as Perceived in Our Time, in CURRent Problems in Psychiatric Diagnosis 139 (Hoch \& Zubin ed. 1953). 
Condemnation can have no effect-favorable or unfavorable-in a high though unknown percentage of cases. Some psychotics, of course, cannot comprehend, consciously or unconsciously, the informational content of what is said to them. ${ }^{46}$ Some mental defectives can perceive that they are being censored, and weep; but the justification of the criticism may be wholly lost by virtue of a low intelligence function, so that no appropriate memory imprint occurs. ${ }^{47}$ Certain neurotic types accept whatever hard judgments are passed upon them and simply add them to the repetitive themes already employed as part of the subjective suffering which characterizes their illness but which does not reform their conduct. ${ }^{48}$ Psychopathic characters are unlikely to be moved by the addition of another denunciation. ${ }^{49}$ Many appear driven by unconscious cravings to be attacked by powerful figures; denunciation by a court is experienced as a triumph and signifies that another father-substitute has fallen into the trap and liberated another store of destructive aggression.

The Dissenter. The reference here is to the individual whose violation of obligation is self-justified by rejecting the ideological system in the name of which primary and sanctioning norms are defined and applied. This rejection may, if extreme, manifest itself in service to the ideology of a foreign power (as in espionage). Such an ideology may affirm a world revolutionary conception against the "counterreviolutionary" ideas that prevail among local authorities. ${ }^{50}$ Or, the counterideological system may be as yet invoked by no foreign power; indeed, its supporters may be numbered on the fingers of one hand. Or, the ideology may champion a religious rather than a secular system; the religion may or may not be strongly entrenched abroad, and it may claim millions of adherents or a handful. ${ }^{51}$ The latter cases-taken in conjunction with isolated political prophets-often merge into one of the preceding categories (especially that of the diseased). ${ }^{52}$

A judged offender may refrain from objecting to an adverse legal action and content himself with attacking the validity of the whole system of which the legal arrangements are a detail, or he may focus upon the legal order itself. In either event, he may be thoroughly immunized against any condemnation sanctions directed against him. A trained intelligence agent from a foreign power, a disciplined revolutionary conspirator, a fanatically devout religionist

46. Particularly those suffering from severe organic brain disease. See ENGLISH \& Finch, Introduction to Psychiatry chs. 18-19 (2d ed. 1957).

47. Id. ch. 20.

48. See Alexander \& Staub, The Criminal, The Judge and The Public 93 (rev. ed. 1956).

49. See Cleckley, The Mask of Sanity (3d ed. 1955).

50. See Elliott, Crime in Modern Society 179-82 (1952); Hoover, Masters of Deceit (1958); West, The Meaning of Treason (1947).

51. See Elliott, Crime in Modern Society 187-88, 193-94 (1952); 2 Emerson \& Haber, Political and Civil Rights in the United States 1176-96 (2d ed. 1958); Festinger, Riecken \& Schacter, When Prophecy fails (1956).

52. See Lasswell, Psychopathology and Politics (1930) ; Lasswell, Power and Personalty (1948); Zink, A Case Study of a Political Boss, 1 Psychiatry 527 (1938). 
-all have become accustomed to assuming that they will be "reviled" among men, that, indeed, every assault is a sign of the immorality and weakness of those who are opposed to their ideology.

To be sure, not all dissenters are so exquisitely trained and impervious. Among defecting agents of foreign powers we have seen the great depth of ethical conflict to which the personalities of even the most trusted experts are susceptible. On the issue of responsibility, one question to consider is whether the condemnation response uttered by a court will capitalize upon existing internal cleavages, or, on the contrary, reweld the clefts of previously unified conviction. ${ }^{53}$

The Provoked and the Tempted. We speak here of opposites. Both categories imply relationships to the environment, the former an exposure to deprivation, the latter to indulgence. Both are estimates of disproportionality, indicating that imposition or opportunity exceeded the range assumed to be determinative for classifying ordinary conduct.

This phenomenon highlights a point that applies to the classification of all conduct, namely, that the classification of any detail of behavior or attitude depends upon the total situation of which it is part. We often revise "snap judgments" about human conduct as more information about environmental and predisposing factors becomes available. The muscle movements that constitute an act are not decisive nor are the content and intensity of conscious and unconscious impulses, moods, and perceptions; such details must always be assessed in the light of the significance of the environment for value indulgence or deprivation.

If the provocations are extreme, such as an unprovoked attack upon one's self or a beloved one, the law speaks of justification and excuse. ${ }^{54}$ Temptations, too, can be exceptionally inviting, as when a poorly paid cashier who handles

53. The usual effect of legal action against indoctrinated revolutionaries in the United States is to assist their propaganda technique of exploiting the courtroom situation. In 1919 and 1920 the Communists were under heavy fire from law enforcement officers in Washington, D.C., and elsewhere over the nation. The first tactic of the Communists was to refuse to testify. But Benjamin Gitlow, Charles Ruthenberg, and Isaac Ferguson developed a more durable tactic of condemning the judge and the court. See HowE \& Coser, The American Communist Party, A Critical History (1919-1957), at 49-60 (1957). See also Gates, The Story of an American Communist (1958). And Professors Lowenstein and Riesman have ably discussed how the Fascists and Nazis used libel and libel law as a major political weapon, and that defamation of opponents is one of the standard devices of political propoganda. See Loewenstein, Legislative Control of Political Extremism in European Democracies (pts. 1-2), 38 Colum. L. Rev. 591, 725 (1938); Riesman, Democracy and Defamation: Control of Group Libel, 42 Colum. L. Rev. 727 (1942); Riesman, Democracy and Defamation: Fair Game and Fair Comment (pts. 1-2), 42 Colum. L. Rev. 1085, 1282 (1942). If libel suits were brought, the courtroom was used as an arena for further vilification and abuse. For a similar tactic in this country, see Gordon, Fascist Field Day in Chicago, 166 The Nation 98 (1948).

54. Model Penal Code $\S 3$ (Tent. Draft No. 8, 1958). See also Note, Manslaughter and the Adequacy of Provocation: The Reasonableness of the Reasonable Man, $106 \mathrm{U}$. PA. L. REv. 1021 (1958). 
great sums has an opportunity to make off with millions. ${ }^{55}$ In everyday speech and in many legal codes, these circumstances are referred to as extenuating or mitigating the violation, but there is some reluctance to recognize them as completely exculpatory, presumably for fear of encouraging deviational conduct. ${ }^{\mathbf{5 6}}$

If extraordinarily provoked or tempted individuals are made direct targets of condemnation, many if not most of them will accept the judgment. Often, they performed the censurable act only after great struggles of conscience, and the battle may be reawakened by the application of a sanction. They will act more cautiously in the future. More important, in point of fact, they are not likely to be faced with such an extraordinary situation again.

The Deceived. Some participants in the sequence of activities that culminate in redressable injury are not informed of the object of the enterprise. ${ }^{57}$ Or, the defendant may be actively misled by the victim. ${ }^{58}$ If such "innocent" ones are made targets of condemnation, they are unlikely to feel pangs of conscience. More probably, some will consider the sanction a provocative act that justifies them in seeking to take advantage of their outlawed state by becoming professional criminals or revolutionaries. ${ }^{59}$ (1947).

55. See Cressey, Other People's Money (1953); Peterson, The Embezzler

56. See, e.g., article 62 of the Italian Penal Code, which provides:

The following circumstances, when they are not constitutive elements thereof or special extenuating circumstances, extenuate the offence:-

(1) Having acted for motives of special moral or social value.

(2) Having reacted when in a state of anger caused by an unjust act of another.

(3) Having acted at the suggestion of a tumultuous crowd ....

(4) Having in crimes against patrimony, or which may in some manner injure patrimony, caused to the victim of the offence patrimonial injury of exceedingly trifling extent.

(5) When an act committed with criminal intent by the injured person, in addition to the act or omission of the guilty party, has co-operated in causing the event to occur.

(6) Having before the trial fully repaired the injury by means of compensation and, when possible, restitution.

An elaborate analysis of the aggravating and mitigating circumstances recognized by American courts appears in Hall, Reduction of Criminal Sentences on Appeal (pts. 1-2), 37 Colvm. L. Rev. 521, 762 (1937). See also the criteria for withholding sentence of imprisonment and for placing a defendant on probation in Model Penal Code $§ 7.01$ (Tent. Draft No. 2, 1954).

57. This problem arises frequently in conspiracy cases in which the question is whether or not original agreement contemplated the subsequent "overt acts." See, e.g., Kotteakos v. United States, 328 U.S. 750 (1946) ; Rex v. Meyrick, 21 Crim. App. R. 94, 45 T.L.R. 421 (Ct. Crim. App. 1929). See also Goldstein, Conspiracy to Defraud the United States, 68 YALE L.J. 405, 410 (1959).

58. The classic study is Hentig, The Criminal and his Victim (1948). The entrapment cases are also relevant. See Donnelly, Judicial Control of Informants, Spies, Stool Pigeons, and Agent Provocateurs, 60 Y ALE L.J. 1091, 1098-15 (1951).

59. Judicial measures against defendants who are conscious of their own rectitude frequently lead to a more generalized rejection of the dominant social system. Eugene 
The Mistaken. A few legal offenders cause harm without desiring to do so. From their own perspective, at least, they are innocent in so far as they took "reasonable precautions." ${ }^{\circ 0}$

The Careless. In contrast are those who did not take precautions that were "reasonable" in the pertinent cultural situation. ${ }^{61}$ The effect of condemnation upon members of this group depends upon their appraisal of themselves, an evaluation that does not invariably coincide with the judgment of a scientific investigator or a decision-maker.

Labelling or, more productively, analyzing the character of the offender is not enough; when the community as a whole is considered, our conception of responsibility brings to mind the degree to which the community is involved in producing the chain of damaging events that are brought to the notice of the court and also the responsiveness of the body politic to court decisions. In some cases, it is obvious without further inquiry that failure to reach a specific decision will arouse public indignation, endanger institutional stability, and subvert the international integrity of democratic institutions. ${ }^{62}$ Nevertheless, an enlightened court may perceive that the community's past record has contributed mightily to the factors that culminated in the controversy and that the community itself is likely to precipitate violation of its own norms in the future. ${ }^{63}$ Looking to the future, however, and weighing the probable response of the public and its leaders, the court may conclude that the community cannot be educated by a court decision, that the decision will provoke some citizens to commit damaging acts against public officials. ${ }^{64}$ In the face of such circumstances, a candid judge must admit that the community is nonresponsible in that it requires a correctional change beyond the potential of the court, in the particular case, to effect. The court must then bow to the lack of insight and understanding on the part of the community with the same logic that it bows to the unwelcome facts of lack of education on the part of an individual defendant. In some instances, the immediate outcome is the same for the whole community and the individual defendant who is not responsible. Both go free. In others, the results diverge. The defendant, though not responsible, is subject to correction and may be required to undergo hospitalization or isolation until he has been reconstructed. The community cannot be dealt with in this fashion by its judicial instrument.

Victor Debs, for example, was sentenced for contempt of court for violating an injunction against railway strikers in 1895 . In prison, Debs spent much of the time reading and shortly announced his conversion to socialism. See 5 Dictionary of AMERICAN BIOGRAPHY 183 (1943).

60. See Hall, Ignorance and Mistake in Criminal Law, 33 IND. L.J. 1 (1957).

61. Codes usually use the terms "recklessness" and "negligence" as categories of culpability. Model Penal Code § 2.02 (Tent. Draft No. 4, 1955).

62. See note 33 supra.

63. See the Little Rock integration opinion, Cooper v. Aaron, 358 U.S. 1 (1958).

64. This seems to have been the view of District Judge Lemley in the Little Rock case. Aaron v. Cooper, 163 F. Supp. 13 (E.D. Ark. 1958). 
The circumstances confronting a court in most cases, however, are by no means so extreme. More commonly, an adverse storm of criticism, accompanied perhaps by sporadic acts of violence, which can be weathered by the courts, is to be anticipated. ${ }^{65}$ Recognition of the community's causal contribution can coexist with a prediction that the community is educable within recognizable limits by such means as a stream of "innovative" decisions. ${ }^{66}$

\section{FURTHER IMPLICATIONS}

Thus far, our discussion of responsibility has outlined some features of the decision-making context which a rational judge may consider when confronted by a controversy occasioning his use of the power of the body politic in directing a negative sanction against a target. We have proposed two sets of principles for his guidance. The first set relates to the content of his thinking; the second to the procedures used in guiding his attention. It is a principle of content when responsibility is defined as the possession of, or a potential for, at least a minimal degree of education in the patterns of the social context relevant to the decision. It is a principle of procedure that spells out the considerations to be given orderly attention in determining how principles of content are to be related to specific contexts, in other words, in determining whether a given target is responsible. An example of a procedural recommendation is the list of potential targets, since it can be used by the thoughtful judge to guide his attention to the possible impact of any negative sanction. It can be employed to emancipate the decision-maker partially from the artful strategies of counsel in presenting their clients' claims. The list of predispositional groups and factors is another procedural guide of the same kind. The most generalized procedural suggestion is the list of the five intellectual tasks to be performed in solving problems. It serves to remind the decision-maker of the recurring dimensions of goal, projection, alternative, trend, and condition. The definition of human dignity as a goal, the specification of the Universal Declaration of Human Rights, and the particularizing of fundamental institutions comprising the American system of public order are matters of content.

65. See the segregation cases, Brown v. Board of Educ., 347 U.S. 483 (1954), 349 U.S. 294 (1955).

66. The demand to impose suffering may be widespread throughout all or many social classes in the body politic and it may peculiarly characterize some interest groups and personalities. During periods of crises, too, sadistic demands may be most active. One must not lose sight of the fact that an examination of a specific culture will show that it is characterized by permissive or even adulatory evaluations of cruelty in the name of punishment. There is no place for cruelty as an end in itself in a value system committed to human dignity. See Ewing, Punishment as Viewed by the Philosophers, 21 CAN. B. Rev. 102 (1943). Royal Commission on Capital Punishment, Report 17 (1953). Concessions made to the glorification of cruelty in the name of punishment are justified only when the net gains outweigh the costs (as to all values involved). Since estimates of the kind required cannot be made by means of automatic rules, the prospects for human dignity are best when decision-makers are human beings who gain no gratification by imposing cruelty. 
Our approach has further implications for a judge. What range of policy alternatives is open to him? The judge (or jury) can indulge a claim advanced by a party by accepting it and thus throw the weight of the community's assets in the balance, or he can deprive a party's claim by rejecting it. If an immediate target is regarded as "responsible," he is open to negative sanctions whose range can be described according to severity or mildness and according to the value involved (for example, rectitude if the defendant is condemned for the violation of a legal norm that embodies ethical and religious injunctions). If a defendant is not regarded as a significantly contributing participant in the controversy before the court, he goes free. If the defendant is judged to be a significantly contributing and responsible participant, he is subject to sanction. If the defendant is judged to be a significantly contributing but nonresponsible participant, our conception of responsibility indicates that he is a correction problem open to measures whose function is to reconstruct the defendant, or to withdraw him from the community, or both (medical treatment or re-education may or may not require withdrawing the individual from the active life of society). Withdrawal is indicated if the defendant is regarded as a highly potential contributing participant in significant deprivations. If the defendant is judged to have learned the proper conduct as a result of his involvement in the current controversy, he may be allowed to go free.

At this point, we may ask about the other participant, someone who has suffered a significant value deprivation as an immediate consequence of the defendant's illegal act. The ordinary course of living subjects everyone to risks of loss or of blocked gain; risk-taking is part of the pattern of culture in any given social context. America's public policy has, by and large, relegated to the individual the burden of insuring himself against misfortune. More recently, under the changing circumstances of contemporary science and technology, our institutions of public order have been modified to include compulsory insurance arrangements, and the community provides supplementary income to the dependents of an individual who has failed to make advance provision for his welfare in the event of adversity. Hence, there are ample institutional precedents for reparation provisions covering the losses of significantly deprived participants. ${ }^{67}$

Our conception of responsibility underlines the difficulty of the problem that confronts a decision-maker in passing back and forth between past and future, and between estimates of significantly contributing participation and responsibility. The first issue to be determined in a controversy, of course, is whether a redressable deprivation was imposed upon the alleged victim. After that come the questions to what extent, if any, the defendant was a participant in the sequence of deprivation, and whether, if a participant, he is responsible.

Consider a few of the issues that arise in chains of inference pursued by a rational decision-maker. Suppose a witness describes the precipitating events of the controversy by this statement: "The defendant struck $X$ with his fist

67. Riesenfeld \& Maxwell, Modern Social Legislation (1950). 
and $X$ fell down dead." How can these events be put in context? Is it to be accepted that the defendant's visible behavior contributed significantly to $X$ 's death? Are we to believe that the blow was part of a sequence of acts consciously designed to damage $X$ ? In answering the second question, that is, to find what is known about the lethality of blows administered to individuals of specified characteristics, expert scientific testimony is useful. In answering the third question, information about the trend in the relations between the defendant and $X$ will be helpful. Had $X$ behaved in a more and more provocative way toward the defendant? Once certain events have been placed in a context of past events, the next step is to relate them to the future. Given information about the predisposition of the defendent to respond vigorously to environmental deprivations of a specified kind, how is he likely to conduct himself under various future contingencies-prompt release under a suspended sentence; release on probation with solemn warning and admonition; a fine; imprisonment for a term of years ; release after reconstructive therapy?

Any judgment of responsibility or nonresponsiblity legitimately rests upon systematic consideration of the whole context in which the precipitating events that led to an action involving the community decision-makers occurred. Judgments of proportionality - the proportions between past and potential environments and predispositions; conscious and unconscious factors; capability and opportunity-are involved.

Ultimately, sanctioning alternatives, such as the condemnation sanction, enter the assessment of the total picture. The following propositions about the condemnation sanction are implicit in the foregoing discussion. Thus far, they have been considered with principal reference to the courts, but they are generalizable for all decision-makers.

1. A decision-maker's condemnation response is supported by self-condemnation in the direct target and resisted by countercondemnation.

Verdicts of "guilty" may be echoed by the condemned in the privacy of his self-estimation; every nuance, ranging from unqualified acceptance to total rejection, is possible. Countercondemnations are directed against the decisionmaker as an individual or against the system in the name of which the condemnation is made. Since the tendency to internalize external evaluations is especially strong among young people, the immature are likely to overreact to condemnations, especially in a culture such as ours in which exhortations to rectitude are deeply embedded in youth-rearing practice. Quite properly, the immature are exempted from full responsibility, since their initiation into the norms and techniques of society is incomplete. This technical finding need not, however, deter an examination of the predispositional status of the young for the purpose of testing the most effective informal sanctioning measure to use as part of the basic educational process of the community.

In the extreme, sanctioning measures of a negative kind have little or no effect upon the subjective outlook of some targets, such as the uninformed. 
2. A condemnation response by a decision-maker is supported by target condemnation among the members of the body politic, or resisted in varying degree.

3. A condemnation response by a decision-maker may affect the strength of factors influencing conscious deterrence, or conscious provocation, to action. ${ }^{68}$

4. The condemnation response may or may not be joined with other deprivations of the target, and with indulgences.

Sometimes the impact of an adverse verdict is found enough; it is expected that the condemned will acknowledge guilt, ask forgiveness and promise to do better in the future. A suspended sentence reflects such an expectation. Quite commonly, on the other hand, the condemnation response is joined with other deprivations. ${ }^{69} \mathrm{Or}$, as the value categories indicate, sanction targets are often the inadvertent recipients of important indulgences. ${ }^{\mathbf{7 0}}$

5. A condemnation response may be accompanied by various perspectives on the part of the decision-maker. His private perspective may accept or resist his external expression. He may estimate the responses of the target and the community accurately or inaccurately.

\section{IMPOSING THE SANCTION}

Of all the events that must enter the decision-maker's consideration, one of the most manageable features is the technique of imposing a condemnation sanction. From the standpoints of legislator and judge, the following questions appear: What are the costs and consequences of attaching a condemnation sanction to a responsibly performed deviation from a particular prescription? What are the net advantages of locating the authority to condemn in one rather than another agency or official? What are the ramifications of selecting one occasion above another, and of arranging the details of the act of condemnation in a particular pattern?

\section{What deviations?}

Assume a businessman who, in determining upon a course of illegal conduct, calculates his behavior in balance-sheet terms and shows no relevant private

68. Conscious deterrence refers to the situation in which an individual who thinks of performing an act in violation of a rule refrains from the performance because he recalls the existence of the rule, the probability of condemnation and other adverse consequences of violation. Conscious provocation, in contrast, refers to consideration of violation because the actor objects to the rule itself or to an application of the rule that he regards as unjust. Conscious provocation is commonly connected with the affairs of an organization that is internally deeply divided.

69. Language of deprivation in terms of rectitude is often mixed with terms of ridicule and contempt, terms relating to respect. In the past, deprivations of well-being have been closely associated with condemnation (such as hanging or mutilation) and of wealth (fines, imprisonment). Other deprivations include loss of civil rights, dissolution of the family, and denials of access to education or current enlightenment.

70. Such as probation, good time laws, parole, commutation of sentence, and pardon. See Rubin, Crime and Juvenile Delinquency (1958). 
pathology. The legislator has decided to retain a market regulation even though not many members of the business community are morally disturbed by a violation, and only a few articulate economists favor the regulation in the hope of protecting a free-market structure. Will a condemnation sanction contribute to the aims of the legislation; will such a sanction diminish the temptation to deviate and thus protect the market? Even if severe sanctions are deemed indispensable, whether the use of condemnation will contribute to adherence remains a key question. To some extent, the solution may be aided by expert study and advice. $^{71}$ The effective severity of a sanction must, as a rule, depend upon the intensity of the conviction with which the norm is accepted. That intensity, in turn, can be fostered by condemnatory utterances which set the model for speech, thought, and deed. In a specific legislative context, relevant guidance may be obtained from expert interviewing of community leaders and rank-and-file members, and from comparative study of enforcement attempts. Today the body of comparative information is not large. One purpose of this discussion of responsibility and the isolation of one among many sanctioning measures is to focus active scientific, scholarly, and administrative energies upon the need for establishing sound principles for norm and sanction selection.

We emphasize that the official employment of terms which, in ordinary usage, convey an idea of responsibility (like "responsibility" itself or "criminal") are condemnations. A principal question for legislators is whether these termsespecially "criminal"-are employed self-consistently and functionally. We suggest that the prevailing connotations of the terms "crime" and "criminal" stand in the way of sound strategy on behalf of the American system of public order. A nonresponsible violation is not a "crime" performed by a "criminal" but an act performed by some one who is not sufficiently educated, or educable to perform a "crime." The nonresponsible participant who has imposed significant deprivations is not a "criminal" but "a correction problem." If the term "crime" is retained for its potential weight as a condemnation sanction, it should be applied only under these conditions: decision-makers believe that the deviation in question inflicts serious damage upon institutions composing the system of public order; decision-makers provide for severe deprivations to be imposed upon those who responsibly perform a deviational act; decision-makers expect to continue to receive, or presently to succeed in obtaining, agreement and support from most of the leaders and the rank and file of the body politic.

\section{Who Condemns?}

The stream of official and unofficial utterances must be organized by the decision-makers themselves, who, presumably, can exercise the greatest direct control in a manner that accomplishes the aim of the sanction in the light of, and with a view to influencing, unofficial condemnatory activities throughout the community. More specifically, with regard to informal expressions of con-

71. See Att'y Gen. Nat'l Comm. Antitrust Rep. ch. 8 (1955). 
demnation, the following objectives may be pursued by legislators, judges and other public officials.

1. To minimize some types of informal expression of condemnation prior to decision.

Our standards of fair trial do not tolerate courtroom demonstrations of vituperative character against a defendant. ${ }^{72}$ The rules of evidence are in part designed to provide a measure of protection to the defendant against condemnatory characterizations prior to the verdict. ${ }^{73}$ We caution counsellors and witnesses; we agree that hostile language and gesture by a judge provide grounds for a declaration of mistrial. ${ }^{74}$ We permit trials to be removed from localities where the perspectives of the community have become prematurely and prejudicially crystallized. ${ }^{\mathbf{7 5}}$ In Great Britain much more vigorous efforts are made to cut down the volume of predecision comment upon a case. ${ }^{76}$

2. To reduce some types of informal condemnation after decision.

Our standards of fairness do not permit us to give public support to the exercise of informal sanctions against an offender who has "paid his debt to society."77 In point of fact, the slate is not wiped clean; not all ex-convicts are restored to their former positions in the community. Furthermore, an ex-

$7 \rightarrow$ Note, The Nature and Consequences of Forensic Misconduct in the Prosecution of a Criminal Case, 54 Colum. L. Rev. 946 (1954) ; Note, Prosecutor Forensic Misconduct"Harmless Error"?, 6 UtAH L. Rev. 108 (1958).

73. One such example is the limitations placed upon the use of character evidence. MCCormick, Evidence § 153 (1954).

74. See, e.g., Butler v. United States, 188 F.2d 24 (D.C. Cir. 1951) ; Billeci v. United States, 184 F.2d 394 (D.C. Cir. 1950).

75. Note, Local Prejudice in Criminal Cases, 54 Harv. L. Rev. 679 (1941) ; Annot., Hostile Sentiment or Prejudice as Ground for Continuance of Criminal Trial, 39 A.L.R.2d 1314 (1955) ; Note, The Right To An Impartial Federal Jury In The Event Of Prejudicial Pretrial Publicity, 53 Colum. L. Rev. 651 (1953); Note Controlling Press and Radio Influence on Trials, 63 HARV. L. REV. 840 (1950).

76. Devlin, The Criminal Prosecution in England 119 (1958).

77. Rubin, Crime and Juvenile Delinguency 140 (1958). And consider the story of Harry Golden, newspaper publisher and author of a current nonfiction bestseller, Only in America. It was revealed that in 1929 he had been sentenced to five years in federal prison for using the mails to defraud. The New York Times editorialized as follows:

Harry Golden of Charlotte, N.C., was certainly unique among this season's authors, and perhaps among any season's authors, in not wanting his book to be a big success. Mr. Golden thought that "Only in America" would sell a few thousand copies among his friends down South and elsewhere who were familiar with his bi-monthly publication called "The Carolina Israelite."

He was disappointed. There is something in Harry Golden's writing that turned his book into a run-away best seller. He had been happily well known in a limited circle. Now he was famous.

What produced the qualities in Mr. Golden that made him seem a timely exponent of American ideas, attitudes and emotions? Adlai Stevenson, who with Chief Justice Warren, ex-Governor Dewey, Carl Sandburg, Fannie Hurst and many other well-known Americans, knew his work, suggests that he had had an experience that "deepened his understanding, lengthened his vision, and enlarged his heart." One 
convict often cannot obtain a fresh start even at a much lower rung on the ladder than that which he forfeited by his offense. ${ }^{78}$ Officially, the reinstatement of ex-convicts in the community is encouraged, since failure in bridging the gap toward a socially acceptable livelihood will increase the chances of further offenses. Moreover, public-spirited individuals and persons who have had intimate reasons for understanding the problem of the social returnee join informally in creating private associations to aid the former offender. ${ }^{79}$

3. To increase some types of informal condemnation prior to decision.

A prevalent "law-abiding sense" which provisionally condemns conduct that violates a prescription is an effective instrument of community control. If individuals who become aware of the apparent offense tolerate it and refuse to invoke the official machinery of the body politic, the prescription in question is nominal, not effective, law. The prescription has, in fact, become moribund; its continued inclusion in the code of the community is an invitation to blackmail rather than obedience. ${ }^{80}$ In some instances, however, the salient factors may be quite different. The lethargic response may derive from a disillusioned estimate of the integrity of the public prosecutors, courts, and correctional agencies. Evidence of efficiency and decency will quickly revive an active invoking function to strengthen the applying function.

4. To increase certain types of informal condemnation after decision.

Often the decision of a court is treated by the public media with complete indifference or even adverse comment. Consequently, the sanctioning impact of the official condemnation delivered in the name of the community is diminished. Official policy, to continue to support the prescription at stake, needs more outspoken assistance from the informal elements of society. Such an objective can be sought by many well-established methods, including the law enforcers' direct appeals for active support.

With the interplay between official and unofficial expressions of condemnation in mind, what officials are likely to prove most effective with what targets? American judicial practice has not widely experimented in this realm. The

experience was an episode in early life that landed him in a Federal prison for misuse of the mails.

So now Harry Golden, like another beloved author, who wrote under the name of O. Henry, is "exposed." But the real exposure is of an unpremeditated sort: It is a view of a man's heart, of a lovable philosopher who truly spoke for America, contributing to our current mood an integration of New York's East Side with a section of the Old South. He need no longer fear success. If he was rightly penalized a quarter of a century ago for a youthful error, he is now rightly rewarded and honored for the highly endowed man he so evidently has become.

N.Y. Times, Sept. $21,1958, \S 4$, p. 8 E, col. 1 .

78. Rubin, Crime and Juvenile Delinquency 140-57 (1958).

79. Ibid. See also American Prison Ass'n, A Manual of Correctional StandARds 379-89 (1954) ; American Prison Ass'n, Services to the Discharged Offender, in CONTEMPORY CoRReCTION 380 (Tappan ed. 1951).

80. The laws dealing with homosexuality provide one example. Ploscowe, Sex AND THE LAW 195, 209-10 (1951). 
jury is limited to a terse "guilty" or "not guilty"; and the trial judge is expected to utter only whatever statements of the public conscience are appropriate in the concrete case. As a rule, appellate judges conduct themselves with sufficient solemnity to give great weight to their remarks, whether issued for the court or in dissent. In contrast, the atmosphere of many lower tribunals renders them entirely inappropriate to expatiate upon any matter of conscience. Little ingenuity is required to propose workable ways of modifying the flow of judicial business so as to permit courts to recapture the atmosphere and the integrity of judicial tribunals.

\section{When and How?}

A great deal of experience in the administration of the condemnation sanction is available and may be gathered by proper methods of interviewing and of documentary research. For a random example, national cultures differ in the allowable degrees of vituperative denunciation they expect and exact from those who play the role of official spokesmen. Differences corresponding to social class are observable. Norms vary according to the degree of involvement with, and exposure to, environments that cut across classes (or fail to include all the members of a class). Many expect Quakers to be more soft-spoken than Jehovah's Witnesses; we are not astonished if the graduate of an Ivy League college has a temperate mode of speech. Crisis situations put men on edge and push voices up; adjectives are wilder as verbs are more imperative. Personality factors enter; irascibility is a mark of the inhibited-rage type, for example. Vituperative denunciation has sometimes backfired; by contrast, however, softspokenness has aroused community fear of somnolence or corruption in the judicial branch. These responses are often predictable by the use of methods and principles presently at the disposal of advisors whose talents are available to the courts.

\section{Concuusion}

In brief, we regard the decision-maker's designation of a defendant as responsible or nonresponsible to be a determination that rationally presupposes an orderly intellectual process in which individual and collective factors in the social context have been considered. Since we postulate human dignity as the overriding ideal goal of our society, the choice of targets for applying sanctions calls for prior judgments of responsibility. Assuming that a situation of damage has occurred in which the potential object of sanction is involved, the main question is whether the defendant has sufficiently mastered the appropriate norms and operating techniques to enable him to participate in the life of the community in standard fashion. If educated, in this sense, the defendant is educable by threat or application of the sanctioning system. If, on the contrary, the defendant is not educated, he should be reconstructed with the aim of being made amenable to sanctions. When responsible, a defendant is sanctionable; when nonresponsible, he is a corrective problem. All sanctions, including con- 
demnation, are appropriate when directed at individuals who are educated and capable of learning - for they are educable.

The conception of responsibility outlined here is explicitly limited to the problem of identifying responsibility at issue in those controversies in which the community is both a party and the decision-maker. Presumably, these cases involve deprivations, actually or potentially inflicted upon the institutions of public order, of a magnitude that justifies community initiative as well as judgment. By an analysis of nonresponsible participants who have imposed significant deprivations, we have attempted to show how our legislators, in particular, can contribute to the integrity of the legal process by substituting for the unfortunate confusion of "criminal" and "civil" a coherent conception in which distinctions are drawn according to: severity or mildness of deprivation to public order; severity or mildness of sanction for those who are responsible factors in deprivations; corrective measures of reconstruction or withdrawal for those who are nonresponsible participants in significant deprivations. The idea of responsibility outlined in these pages can readily be extended to controversies in the realm of private arrangements, particularly contract and tort. But the most pressing need appears to be in connection with the vast domain of public controversies. In this arena, an adequate jurisprudential doctrine of responsibility should provide an intellectual tool contributing to the requirements of legal scholarship and public policy. 